\title{
Synthesis and Characterization of Quinoidal Diketopyrrolopyrrole Derivatives with Exceptionally High Electron Affinities
}

\author{
Suman Ray, ${ }^{\dagger}$ Shikha Sharma, ${ }^{\dagger}$ Ulrike Salzner, ${ }^{\dagger}$ and Satish Patil ${ }^{*}{ }^{\dagger} \odot$ \\ ${ }^{\dagger}$ Solid State and Structural Chemistry Unit, Indian Institute of Science, Bangalore 560012, India \\ ${ }^{\ddagger}$ Department of Chemistry, Bilkent University, Ankara 06800, Turkey
}

Supporting Information

ABSTRACT: Open-shell singlet biradicaloids are short-lived intermediates, but they exhibit fascinating properties for spinbased devices. Therefore, understanding the nature of their electronic structure and stability is critical for harnessing them in optoelectronic or spintronic devices. Toward this goal, we have synthesized a series of diketopyrrolopyrrole-based quinoidal molecules to investigate the contribution and relative importance of the biradical form on the ground-state electronic structure and distribution of spin density. Possibility of crossover from a closedshell to an open-shell structure with increase in the $\mathrm{C}=\mathrm{C} / \mathrm{C}-\mathrm{C}$ conjugation length was investigated. The ground-state properties were systematically investigated by nuclear magnetic resonance (NMR) spectroscopy, single-crystal X-ray diffraction, and electrochemical studies. Furthermore, $n$-doping has been carried out in solution at ambient conditions to understand the nature of doped species and demonstrate air stability. Doped species were probed by UV-visible and electron spin resonance (ESR) spectroscopy to unambiguously establish the generation of anionic species in solution. Experimental results are complemented by theoretical calculations to provide insight into the trend toward biradicaloid spin states with increasing conjugation length.

\section{INTRODUCTION}

$\pi$-Conjugated quinoidal molecules have emerged as promising materials because of their air stable n-channel electron transport in organic field-effect transistors, ${ }^{1-8}$ near-infrared (NIR) absorption, ${ }^{9-12}$ and nonlinear optical properties. ${ }^{12-14}$ Recent studies have also revealed the existence of open-shell biradical character for a series of donor-acceptor-based $\pi$-conjugated quinoidal molecules. ${ }^{13-18}$ Considering the inherent chemical reactivity of open-shell biradicals at ambient atmosphere, such properties are quite unusual. ${ }^{15}$ In these molecular systems, the contorted quinoidal forms with closed-shell singlet electronic ground states are strongly stabilized by $\pi$-electron delocalization along the oligoene-like inter-ring $\mathrm{C}=\mathrm{C} / \mathrm{C}-\mathrm{C}$ alternating pattern. ${ }^{19}$ Contributions from closed-shell and open-shell forms through quinoid-aromatic resonance impart biradical character to these systems. ${ }^{13}$ In general, closed-shell singlet systems have electronic ground states with a large HOMO-LUMO gap. In quinoidal conjugated systems, small energy gaps allow mixing of the HOMO and LUMO, which results in biradical character of the ground states. ${ }^{15}$ The driving force for the emergence of an energetically stable open-shell biradical state is the regaining of the aromaticity of the quinoidal units because of their intrinsic preference for aromatic structures. ${ }^{19,20}$ A key point to consider is that the generation of biradical aromatic-like structures results in the dissociation of a $\pi$-bond of the corresponding quinoidal form, reducing $\pi$-conjugation. The energy required for the dissociation of the $\pi$-bond must be compensated by the gained aromatic resonance energy in the generation of Kekule biradicals. ${ }^{21}$ Accretion of nonaromatic quinoidal units leads to further lowering of the band gap as well as additional aromatic resonance energy, which ultimately drives the crossover from the closed-shell (for short oligomeric chains) to the open-shell form (for extended systems). ${ }^{19}$ Hence, the biradical contribution to the ground-state electronic structure would be determined by the relative weight of aromatic and nonaromatic forms and increase with chain length.

Over the years, numerous open-shell singlet biradicaloids based on quinoidal $\pi$-conjugated molecules have been developed, including but not limited to quinoidal oligothiophenes, ${ }^{18,22-24,}$ thienoacenes, ${ }^{8,11,12,20,25,26}$ and polycyclic hydrocarbons. ${ }^{16,17,21,27-38}$ These molecules with biradical character have many prospective applications in organic electronics, $^{1-8,39-42}$ photonics, $^{9-12,43}$ and spintronics devices. ${ }^{44-47}$ The biradical character index $\left(y_{0}\right)$ and singlet-triplet energy gap $\left(\Delta E_{S-T}\right)$ correlate with third-order nonlinear optical (NLO) responses and magnetic properties of open-shell singlet biradicals. ${ }^{19,48,49}$ However, extended $\pi$ systems possessing large biradical character are generally unstable, which poses a profound challenge for the development of synthetic routes

Received: May 1, 2017

Revised: July 9, 2017

Published: July 10, 2017 
to access extended quinoidal oligomers. Several synthetic approaches have been developed to access such oligomers. For example, Tschitschibabin ${ }^{50,51}$ and Thiele ${ }^{52,53}$ developed synthetic routes to attach phenyl groups to the terminal methylene of reactive $p$-quinodimethanes ( $p$-QDM) and extended $p$-QDMs, resulting in stabilization via resonance effect. Introduction of strong electron-withdrawing groups such as cyano groups at terminal positions leading to a pull-pull (or A- $\pi$-A) type structure is another approach that can stabilize the reactive biradicals e.g, 7,7,8,8-tetracyanoquinodimethane (TCNQ). ${ }^{5,55}$ Alternatively, incorporation of heterocyclic moieties with lower aromatic resonance energy than benzene, like thiophene, into the oligomeric arrangement results in stable quinoidal oligothiophenes and thienoacenes with distinctive biradical character. ${ }^{55}$ End-capping of oligothiophene with dicyanomethylene, increasing its electron-withdrawing ability and lowering the LUMO energy level, has proven to be an efficient way of stabilizing biradicaloid structures. In this regard, tetracyanothienoquinodimethane systems have been recognized as potential materials for $n$-channel organic semiconductors $4,5,56-61$ with reported field-effect electron mobility as high as $0.9 \mathrm{~cm}^{2} \mathrm{~V}^{-1} \mathrm{~s}^{-1}$. Thus, biradicaloid character in quinoidal molecules influences their chemical reactivity, stability, and physical properties. It is therefore worthwhile to explore the molecular underpinning of chemical reactivity and physical properties of $\pi$-conjugated quinoidal oligothiophenes. Here, we systematically address the underlying questions regarding the contribution and relative importance of a biradical character in the ground-state electronic structure of quinoidal molecules. We have also investigated possible crossover from a closed-shell to an open-shell structure with an increase in the effective conjugation length of quinoidal oligothiophenes.

A careful scrutiny of recent literature reveals that diketopyrrolopyrrole-incorporated thio- and thienothio-quinoidal compounds with low-lying LUMO have been reported to show superior n-channel mobility $\left(0.72\right.$ and $0.22 \mathrm{~cm}^{2} \mathrm{~V}^{-1} \mathrm{~s}^{-1}$, respectively). ${ }^{1,2}$ However, exploration of their biradicaloid character is yet to be addressed. Therefore, the central aim of the present study is to (1) develop a facile synthetic method for quinoidal DPP, (2) conduct a systematic investigation of their geometries and electronic ground states, (3) investigate conjugation length-dependent evolution of biradicaloid character, and (4) characterize the nature of anionic species after ntype doping, through a combination of theoretical and experimental approaches.

\section{THEORETICAL METHODS}

Density functional theory (DFT) and time-dependent density functional theory (TDDFT) calculations on compounds 1-3 (Figure 1) were carried out with the Gaussian 09 program. ${ }^{62}$ The alkane chains of the synthesized molecules were replaced by methyl groups. As anions and dianions are involved, the calculations were done with the $6-31+\mathrm{G}^{*}$ basis set with diffuse functions. Test calculations for anions and dianions with the 6$311++G^{*}$ basis set did not lead to significant changes. Solvent effects were taken into account with the polarized continuum model (PCM) as implemented in Gaussian 09. Charges were calculated with natural population analysis (NPA).

Assessing the amount of biradical character is a difficult problem for large systems because the number of $\pi$-electrons excludes application of complete active space second perturbation theory (CASPT2). We therefore tested the

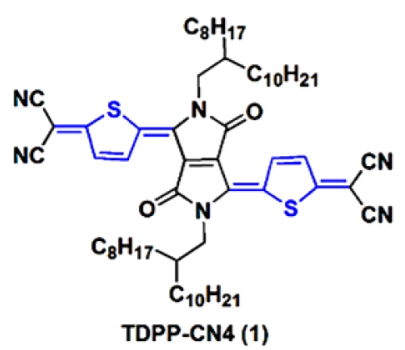

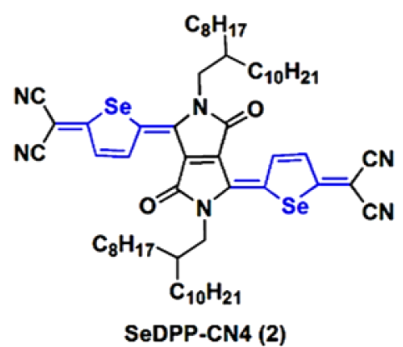

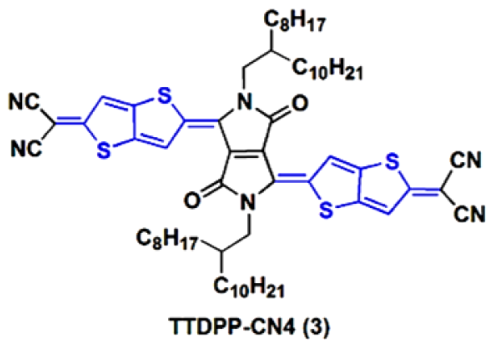

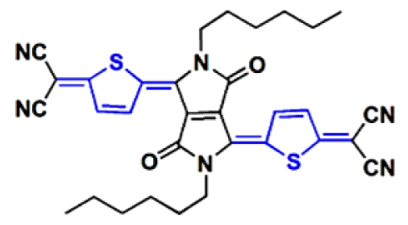

TDPP-HEX-CN4 (4)

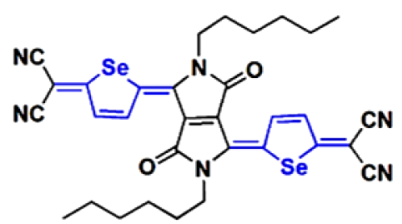

SeDPP-HEX-CN4 (5)

Figure 1. Structures of the synthesized dicyanomethylene-end-capped quinoidal diketopyrrolopyrrole derivatives.

biradical character index $\left(\mathrm{y}_{0}\right),{ }^{19}$ which is based on the unrestricted Hartree-Fock method. We obtained symmetry breaking for all systems, but the wave functions are highly spin contaminated. Upon removal of the first spin contaminant, expectation values of the spin operator increased from 2.68 to over 10. The correct value for biradicaloids is between 0 (strongly interacting electrons) and 1 (noninteracting electrons, 50:50 mixture of degenerate opposite and parallel spin states). A detailed evaluation of spin contamination and spinprojection methods for biradicals was carried out by Davidson and Clark with the conclusion that for large systems, projected UHF and Yamaguchi's method ${ }^{63}$ fail and that broken symmetry DFT remains the most consistent choice. ${ }^{64}$

We tested three density functionals with an increasing amount of exact exchange, B3LYP (20\%), B3P86-30\% (30\%), and $\omega \mathrm{B} 97 \mathrm{X}-\mathrm{D}$ (range-separated functional with $22 \%$ of shortrange and $100 \%$ of long-range exact exchange). As the tendency for symmetry breaking increases with the amount of exact exchange, these calculations alone cannot decide whether systems have closed-shell or biradical ground states. Our final conclusions are therefore based on previous experience with the different density functionals ${ }^{65}$ and the comparison of structural parameters and theoretically predicted spectra with observed spectra.

All systems were calculated with unrestricted DFT and with mixing of the HOMO and LUMO in the initial guess to allow for symmetry breaking. Complete symmetry breaking was observed only with the $\omega \mathrm{B} 97 \mathrm{X}-\mathrm{D}$ functional for the neutral form of TTDPP-CN4, the largest of the investigated molecules. The expectation value of the spin operator is 0.97 , and the singlet biradical is $1.37 \mathrm{kcal} / \mathrm{mol}$ more stable than the closedshell form. The triplet state lies $7.12 \mathrm{kcal} / \mathrm{mol}$ above the biradical. A stability check of the wave function (stable = opt keyword in G09) at the B3P86-30\%/6-31+G* level in DCM 
produced a broken symmetry solution that is $0.07 \mathrm{kcal} / \mathrm{mol}$ more stable than the closed shell form and has an expectation value of the spin operator of 0.18 . The small energy difference and small expectation value of the spin operator is an indication that the ground state is closed-shell singlet at this level of theory. The TTDPP-CN4 dianion calculated with $\omega$ B97X-D at the geometry of the neutral form breaks the symmetry, but has a very small expectation value of the spin operator (0.35). Upon structure optimization it returns to closed-shell. A stability check confirmed that the dianion is a closed-shell singlet at this level of theory. No symmetry breaking was observed with B3LYP and B3P86-30\% functionals for any of the other species.

Comparison of bond length alternation of closed-shell and open-shell TTDPP-CN4 (Table S1, Supporting Information (SI)) reveals that the open-shell form has significantly less bond length alternation (BLA) than the closed-shell singlet. Unfortunately, TTDPP-CN4 could not be crystallized, so that experimental BLA is not available for comparison. However, the absorption spectra of the closed-shell and biradical forms (Figure S1) differ significantly. Comparison with experiment reveals major discrepancies between theory and experiment for the biradical but good agreement for the closed-shell singlet. On the basis of these findings, it is concluded that the range-separated $\omega$ B97X-D functional with $100 \%$ of long-range exact exchange exaggerates the biradical character of TTDPP-CN4 and that the observed species is the closed-shell form as predicted with the global hybrids. For TDPP-CN4 and SeDPP-CN4, B3P86-30\% and $\omega$ B97X-D closed-shell calculations match the experiment very well, and B3LYP underestimates BLA. The match of calculated and experimental structures confirms the closed-shell nature of these molecules.

The tendency toward symmetry breaking with $\omega$ B97X-D indicates that the neutral form and the dianion of TTDPP-CN4 are borderline between closed-shell and biradicaloid, but are not true biradicals. As TTDPP-CN4 with two additional double bonds compared to TDPP-CN4 and SeDPP-CN4 is close to become a biradical, we replaced the thiophene rings in TDPP-CN4 with bithiophenes. The new compound with only two more double bonds than TTDPP-CN4 breaks the symmetry already with the B3P86-30\% global hybrid functional and is therefore a biradical.

On the basis of the above considerations, we choose the B3P86-30\% global hybrid functional for most of the following theoretical analysis, and the reported results are obtained on closed-shell species. Only for ionization energies (IE)s and electron affinities (EA)s we choose to employ $\omega$ B97X-D because our previous studies ${ }^{65}$ showed that B3P $86-30 \%$ tends to overestimate IPs and EAs.

\section{RESULTS AND DISCUSSION}

3.1. Synthesis. Derivatives of quinoidal diketopyrrolopyrrole as shown in Figure 1 have been named as TDPP-CN4, SeDPP-CN4, TTDPP-CN4, TDPP-HEX-CN4, and SeDPPHEX-CN4. The synthetic route is shown in Scheme 1. They were synthesized according to the literature-reported procedure with necessary modifications from the corresponding dibromosubstituted DPP precursors using malononitrile and sodium hydride through a Pd-catalyzed Takahashi coupling reaction in anhydrous tetrahydrofuran. ${ }^{1,2,58}$ The detailed synthetic procedures for the preparation of these quinoidal molecules are described in the SI. We obtained satisfactory yields by aerial
Scheme 1. Synthesis of Dicyanomethylene-End-Capped Quinoidal Diketopyrrolopyrrole Derivatives
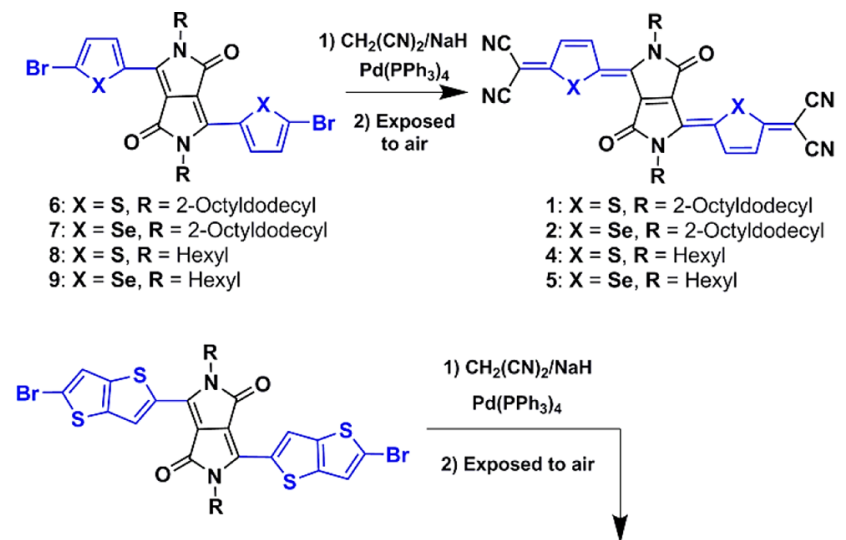

10: $R=2-$ Octyldodecyl

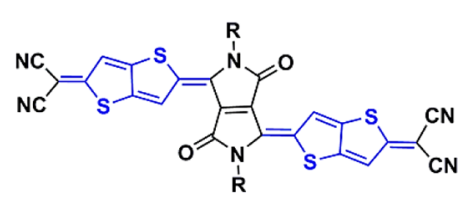

3: $\mathbf{R}=2-$ Octyldodecyl

oxidation of the corresponding dihydro compounds instead of using saturated bromine water as the oxidizing reagent as was reported previously in the literature. ${ }^{66}$ As a result, the brominated side products have been avoided.

The chemical structures of these molecules were established by ${ }^{1} \mathrm{H}$ and ${ }^{13} \mathrm{C}$ NMR and ESI-MS (SI). Furthermore, we have grown single crystals of TDPP-HEX-CN4 and SeDPP-HEXCN4 to investigate the quinoidal nature of these molecules.

3.2. Electrochemical and Optical Properties. As is evident from the cyclic voltammetric analysis (CV) in dry dichloromethane (DCM) (Figure 2), all of the compounds show reversible two-electron reduction waves, while anodic sweeping shows no oxidation waves. $\omega \mathrm{B} 97 \mathrm{X}-\mathrm{D} / 6-31+\mathrm{G}^{*} /$ DCM calculations predict vertical $\triangle$ SCF IEs of $6.25 \mathrm{eV}$ (TDPP-CN4), $6.23 \mathrm{eV}$ (SeDPP-CN4), and $5.81 \mathrm{eV}$ (TTDPP-

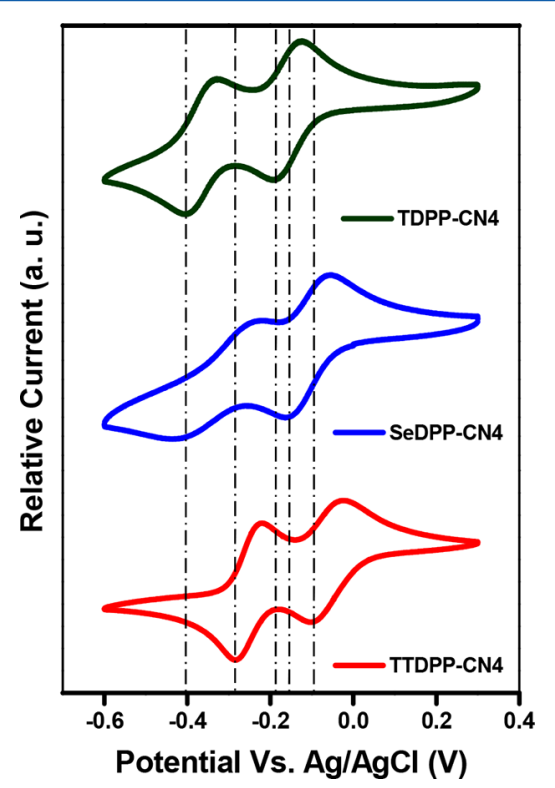

Figure 2. Cyclic voltammograms of three quinoidal DPP derivatives with varied donor units. 
Table 1. Summary of the Electrochemical and Photophysical Data of TDPP-CN4, SeDPP-CN4, and TTDPP-CN4

\begin{tabular}{|c|c|c|c|c|c|c|c|}
\hline \multirow[b]{2}{*}{ molecules } & \multicolumn{4}{|c|}{ electrochemical properties ${ }^{a}$} & \multicolumn{3}{|c|}{ optical properties } \\
\hline & $E_{\text {red 1 }}^{\mathrm{O}}(\mathrm{V})$ & $E_{\text {red 2 }}^{\mathrm{O}}(\mathrm{V})$ & $\left(E_{\text {red1 }}^{\mathrm{O}}\right)-\left(E_{\text {red2 }}^{\mathrm{O}}\right)$ & $E_{\text {LUMO }}^{b}(\mathrm{eV})$ & $\mathrm{EA1}^{c}(\mathrm{eV})$ & $\Delta E_{\mathrm{g}}^{\text {opt }}(\mathrm{eV})$ & $\varepsilon_{\max }^{d}(\mathrm{eV})$ \\
\hline TDPP-CN4 & -0.19 & -0.40 & 0.21 & -4.47 & 4.46 & 1.72 & 1.97 \\
\hline SeDPP-CN4 & -0.16 & -0.41 & 0.25 & -4.50 & 4.42 & 1.71 & 1.95 \\
\hline TTDPP-CN4 & -0.09 & -0.28 & 0.19 & -4.53 & 4.47 & 1.41 & 1.66 \\
\hline
\end{tabular}

${ }^{a} \mathrm{Cyclic}$ voltammetric analyses were carried out with reference to the $\mathrm{Ag} / \mathrm{AgCl}$ electrode and ferrocene/ferrocenium $(\mathrm{Fc} / \mathrm{Fc}+)$ couple as standard. ${ }^{b}$ LUMO energy levels were calculated using the onset of reduction according to the formula: $E_{\mathrm{LUMO}}=-\left(E_{\text {red }}+4.5\right) \mathrm{eV}$. ${ }^{c} \mathrm{EAl}$ are vertical EAs calculated at $\omega \mathrm{B} 97 \mathrm{X}-\mathrm{D} / 6-31+\mathrm{G}^{*}$ in DCM. ${ }^{a}$ Theoretical excitation energies are calculated at TDB3P $86-30 \% / 6-31+\mathrm{G}^{*}$ in $\mathrm{DCM}$ and correspond to peak maxima, not onset of absorption.

CN4). These high IEs rationalize the absence of oxidation waves in electrochemical studies.

Table 1 compares the half-wave reduction potentials and "LUMO energy levels" determined from the onset of the first reduction wave of all compounds. Upon sweeping down to $-0.7 \mathrm{~V}$, TDPP-CN4 demonstrates reversible two-electron reduction waves with half-wave potentials at -0.19 and -0.40 $\mathrm{V}$ vs Ag/AgCl. SeDPP-CN4 shows similar behavior with halfwave potentials at -0.16 and $-0.41 \mathrm{~V}$.

The two-electron-reduction process involves reduction of the $\pi$-system to a radical anion followed by a dianion, stabilized by the electron-withdrawing terminal dicyanomethylene groups. The potential separation between the two reduction peaks of $0.20 \mathrm{~V}$ (for TDPP-CN4) and $0.25 \mathrm{~V}$ (for SeDPP-CN4) suggests two successive one-electron reductions and indicates high stability of anionic species in solution at room temperature. It is obvious that extension of the molecular size leads to the lowering of the LUMO energy level in TTDPP-CN4 compared to TDPP-CN4 and SeDPP-CN4 (Table 1). These findings are confirmed by DFT calculations. All three species have large first- and second-electron affinities (EAs) according to the $\omega \mathrm{B} 97 \mathrm{X}-\mathrm{D} / 6-31+\mathrm{G}^{*} \Delta \mathrm{SCF}$ calculations in DCM. The vertical first EAs (EA1) are included in Table 1 . The values differ only by less than $0.08 \mathrm{eV}$ from experiment. The adiabatic EA1 and EA2 values are 4.71 and $4.31 \mathrm{eV}$ (TDPP-CN4), 4.67 and $4.29 \mathrm{eV}$ (SeDPP-CN4), and 4.74 and $4.49 \mathrm{eV}$ (TTDPPCN4). The differences between first and second EAs are greater than those between the two reduction potentials, but the exceptional stability of anions and dianions is clearly reproduced. The first EAs of TDPP-CN4, SeDPP-CN4, and TTDPP-CN4 are very similar, but like found in experiment, EA2 of TTDPP-CN4 is $\sim 0.2 \mathrm{eV}$ greater than those of the other two molecules. The higher second EA of TTDPP-CN4 can be attributed to greater delocalization of injected negative charge in the larger oligomer and alleviation of the on-site Coulombic interaction among the two electrons as the oligomer size grows longer. ${ }^{4,60}$ The high EAs meet the criteria for facile electron injection and charge transport in ambient conditions similar to those for other quinoidal thieno derivatives.

Analysis of the charge distributions with NPA reveals that the additional electrons acquired during the two reduction steps are distributed over the entire molecules. For example, in SeDPPCN4 during the first reduction step, DPP accepts $0.31 \mathrm{e}$, each selenophene accepts 0.19 e, and each dicyanomethylene unit accepts 0.15 e. The second reduction step distributes the charges even more evenly with DPP receiving $0.27 \mathrm{e}$, selenophene receiving $0.18 \mathrm{e}$, and dicyanomethylene receiving $0.19 \mathrm{e}$. Thus, the dicyanomethylene units increase the EAs by participating in the charge accommodation, but the charges are not localized at the terminal groups.
Optical properties of TDPP-CN4, SeDPP-CN4, and TTDPP-CN4 have been investigated by UV-visible spectroscopy and TDDFT calculations. The neutral molecules show intense and structured electronic bands at around 649,651, and $773 \mathrm{~nm}$ respectively, with shoulders at 606,607 , and $703 \mathrm{~nm}$ (Figure 3a). The low-energy vibronic features can be attributed
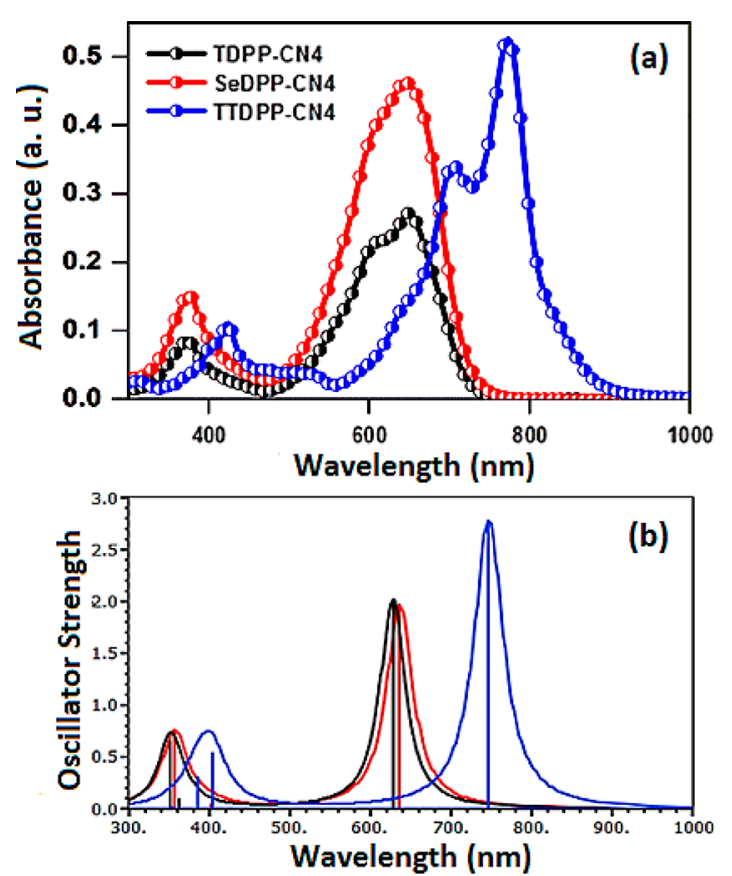

Figure 3. Comparison of UV-visible/NIR spectrum of TDPP-CN4, SeDPP-CN4, and TTDPP-CN4; (a) experimental and (b) theoretically predicted.

to rigid heteroquinoid arrangement of the chromophores. ${ }^{60}$ The bands are red-shifted in comparison with the electronic transitions of aromatic oligothiophenes of similar size. ${ }^{67}$ TDB3P86-30\% calculations in the presence of DCM reproduce the spectra with errors of under $25 \mathrm{~nm} \quad(<0.06$ $\mathrm{eV})$. All three systems have additional weak higher energy transitions at around $400-450 \mathrm{~nm}$ with oscillator strengths of about 0.7. In contrast to the spectra shown in Figure 3a, where TDPP-CN4 absorbs with lower intensity than SeDPP-CN4, theory predicts similar oscillator strengths $(f)$ for TDPP-CN4 $(f=2.02)$ and SeDPP-CN4 $(f=1.96)$ but stronger absorption for TTDPP-CN4 $(f=2.78)$. The transitions are dominated by promotion of one electron from the HOMO to the LUMO, but the HOMO-LUMO transitions account only for $74-78 \%$ of the change between the ground and excited state. This indicates that many additional orbital replacements with small individual 
contributions that represent electronic relaxation effects are important for the S0 to S1 transition.

3.3. Doping Studies. The reversible two-stage reduction steps observed during $\mathrm{CV}$ can also be produced with chemical doping through gradual addition of air stable n-dopant tetrabutylammoniumborohydride $\left(\mathrm{TBABH}_{4}\right)$ in degassed anhydrous chlorobenzene. The doping process has been monitored by absorption and electron spin resonance spectroscopy (ESR). During the course of titration of a solution of TDPP-CN4 in chlorobenzene with $\mathrm{TBABH}_{4}$, the color of the solution gradually changed from blue to green. This change of color was accompanied by the gradual emergence of three new peaks at 878,366 , and $980 \mathrm{~nm}$ for the radical anion and diminution of the peak at $649 \mathrm{~nm}$ of the neutral species (Figure 4). The formation of the odd-electron radical anion is
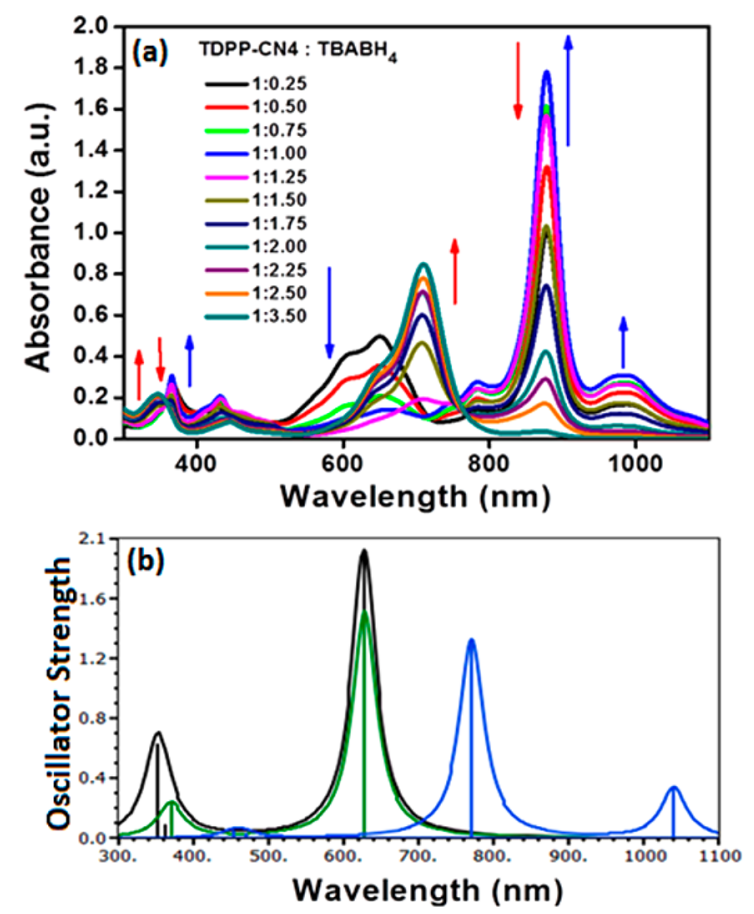

Figure 4. UV-visible spectrum of neutral, radical anion, and dianion of TDPP-CN4 during doping; (a) experimental (ratios are given in equivalents) and (b) theoretically predicted at B3P86-30\%/6-31+G* (black: neutral, blue: anion, green: dianion).

confirmed by observation of a strong EPR signal without fine structure. Further addition of $\mathrm{TBABH}_{4}$ resulted in the emergence of dianion absorption peaks at 710 and $346 \mathrm{~nm}$ with simultaneous reduction of radical anion peaks. The color of the solution changed to bluish green upon addition of two or more equiv of $\mathrm{TBABH}_{4}$ because of the exclusive formation of dianionic species, which are silent in EPR. In particular, the EPR measurement was performed on five different solutions of TDPP-CN4 with varying proportions of the $\mathrm{TBABH}_{4}$ dopant $(0.5,1.0,1.5,1.9$, and 2.0 equiv, respectively), and the results are shown in Figure 5. From the EPR data, it is obvious that EPR intensity reaches a maximum when 1.0 equiv of dopant is added, indicating the maximum concentration of radical anion. On addition of 1.5 equiv of $\mathrm{TBABH}_{4}$, the signal intensity decreases due to the formation of dianion and reduction in the concentration of radical anion. There was no observable EPR signal when 2.0 or more equiv of $\mathrm{TBABH}_{4}$ were added because of formation of the even-electron dianion species. The

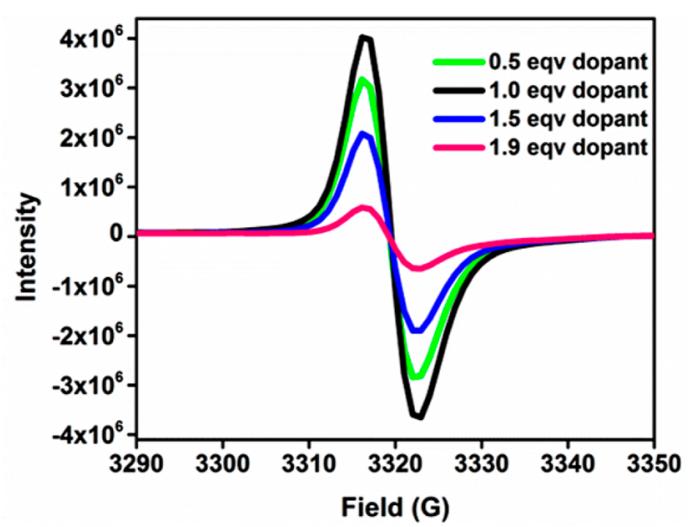

Figure 5. EPR spectrum of TDPP-CN4 after doping with varying concentrations of $\mathrm{TBABH}_{4}$.

proposed structural changes upon two successive electron injections leading to radical anion and dianion are depicted in Scheme 2. $\mathrm{TBABH}_{4}$ acts as a one-electron reducing agent in

Scheme 2. Proposed Structural Changes in TDPP-CN4 on Reduction to Radical Anion and Dianion

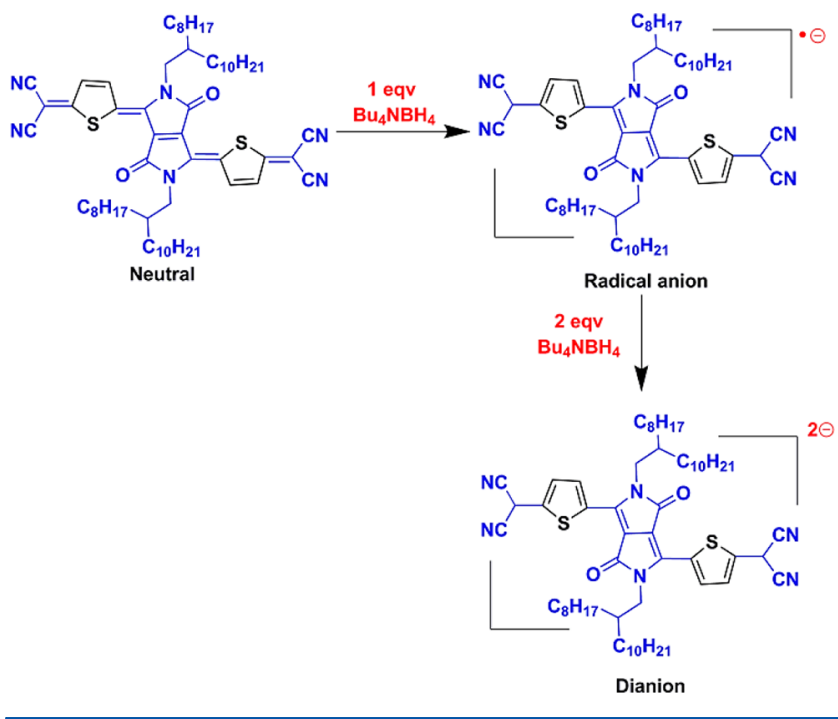

organic solvents. The remarkable ambient stability of both of the anionic species makes it possible to further examine their optical properties.

Theoretically predicted spectra (Figure $4 \mathrm{~b}$ ) for anions and dianions reproduce the observed spectra very well. The largest deviation is obtained for the anion peak that is predicted at 772 $\mathrm{nm}$ but observed at $878 \mathrm{~nm}$. This error of $106 \mathrm{~nm}$ corresponds to $0.20 \mathrm{eV}$, which is normal and acceptable for TDDFT calculations. The two low energy peaks of the anion are almost pure HOMO-LUMO transitions of $\alpha$ - and $\beta$-electrons (1042 and $772 \mathrm{~nm}$, respectively). The dianion peak is a pure HOMO-LUMO transition as well.

3.4. X-ray Single Crystal and Theoretical Analysis. Xray single-crystal diffraction study unveils valuable information about the molecular organization and interactions in the solid state. Unfortunately, we failed to grow single crystals for the molecules with long branched dove-tailed like alkyl chains (e.g., TDPP-CN4, SeDPP-CN4, and TTDPP-CN4) and could not establish the nature of intermolecular interactions. However, we have grown single crystals for compounds with shorter alkyl 

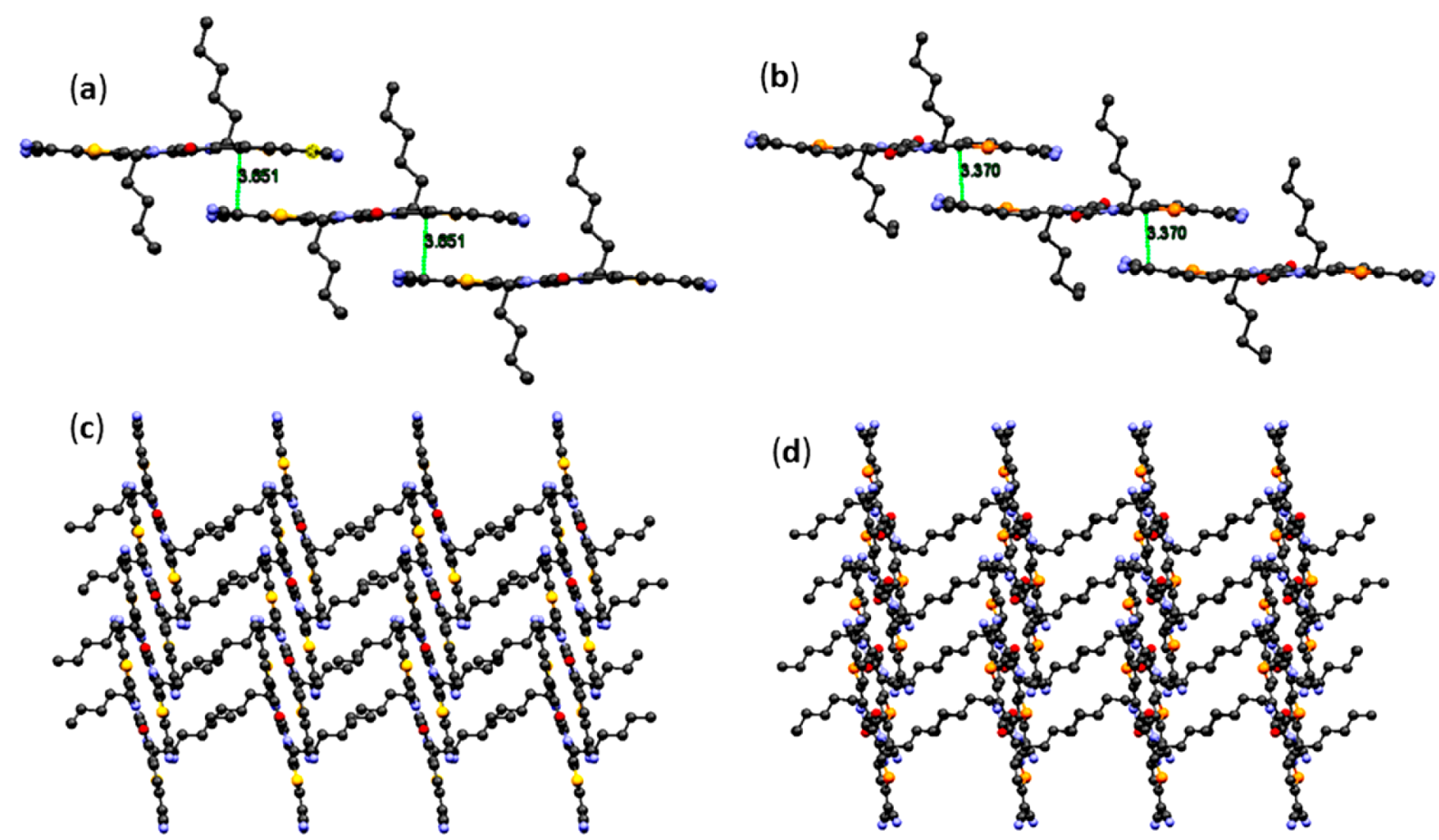

Figure 6. Slipped face-to-face $\pi-\pi$ stacking pattern: (a) TDPP-HEX-CN4 and (b) SeDPP-HEX-CN4. Lamellar packing patterns viewed along $b$ axis: (c) TDPP-HEX-CN4 and (d) SeDPP-HEX-CN4.

(hexyl) chains, e.g., TDPP-HEX-CN4 and SeDPP-HEX-CN4. Notably, for TTDPP-CN4, a long branched alkyl chain was indispensable to ensure sufficient solubility in organic solvents because of its rigid planar $\pi$-conjugated backbone. The hexyl analogue of TTDPP-CN4 was found to be insoluble in organic solvents, which precludes its physical characterization by NMR spectroscopy and X-ray single-crystal analysis.

Single crystals of both TDPP-HEX-CN4 (CCDC 1520840) and SeDPP-HEX-CN4 (CCDC 1520841) were obtained by slow solvent evaporation from a fairly concentrated $\mathrm{CHCl}_{3}$ solution. Both of the molecules crystallize in a monoclinic lattice system with space group $P 21 / c$. These $\pi$-conjugated quinoidal systems present high planarity with very small interplanar twist angles. For TDPP-HEX-CN4, the angle between the planes containing the DPP moiety and the thiophene ring is $8^{\circ}$, whereas the same for SeDPP-HEX-CN4 is measured to be $10^{\circ}$. The two hexyl groups are oriented above and below the molecular plane owing to the $\mathrm{sp}^{3}$ hybridization. In the context of solid-state packing arrangement, it is pertinent to mention that the ratio between carbon and hydrogen is a critical factor in determining the solid-state packing pattern in arenes and chalcogenoarenes. ${ }^{68}$ Low $\mathrm{C} / \mathrm{H}$ ratios facilitate the $\mathrm{C}-\mathrm{H} / \pi$ molecular interactions, which result in herringbonetype packing in the solid state. ${ }^{66}$ On the contrary, high $\mathrm{C} / \mathrm{H}$ ratios assist $\pi-\pi$ stacking, ${ }^{68}$ associated with the different degrees of slippage along the stacking axis to decrease electrostatic repulsion in the solid state. ${ }^{68,69}$ These dicyanomethylene-end-capped DPP quinoidal molecules have a higher $\mathrm{C} / \mathrm{H}$ ratio compared to their parent aromatic analogues. The aforementioned quinoidal structures exhibit slipped face-to-face $\pi-\pi$ stacking with very large slippage, unlike classical herringbone-type edge-to-face packing shown by corresponding parent aromatic forms of DPP (Figure 6). ${ }^{67}$ For both TDPPHEX-CN4 and SeDPP-HEX-CN4, a lamella-like layered structure with interdigitation of the hexyl substituents on the
DPP ring is observed when viewed along the $b$ axis (Figure 6). Along the long molecular axis direction, the molecules are $\pi$ stacked in two nonequivalent stacks in a slipped face-to-face arrangement with a fairly large slip.

Steric repulsion between the hexyl substituents of the central DPP ring prohibits the perfect face-to-face overlap, thereby imposing a large slippage within the stacks. In both cases, the stacks are packed in alternating columns (Figure S3). The $\pi-\pi$ distances in TDPP-HEX-CN4 and SeDPP-HEX-CN4 are 3.65 and $3.37 \AA$, respectively. For SeDPP-HEX-CN4, the two stacks are twisted by $30.0^{\circ}$. Inspection of the packed structure demonstrates additional intermolecular noncovalent interactions, namely, hydrogen bonding between the $\beta$-hydrogens of the thiophene/selenophene ring and the nitrogen on the

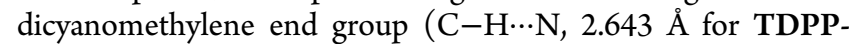
HEX-CN4 and $2.625 \AA$ for SeDPP-HEX-CN4), which holds the two stacks together to give a 3D structure. This stacking pattern can be ascribed to the presence of $\pi / \pi$, S/S or Se/Se, $\mathrm{C}-\mathrm{H} / \pi$, and $\mathrm{C}-\mathrm{H} / \mathrm{N}$ interactions. This unusual $\pi$-stacked motif is of particular interest for organic field-effect transistors. Thus, the large deviation from perfect alignment can, in principle, still confer on materials with significantly improved mobilities. ${ }^{5,6,70,71}$ In brief, the intermolecular nonbonded interactions and strong $\pi-\pi$ stacking act as a major factor responsible for efficient charge transport properties in these quinoidal systems. $^{72,73}$

Structure optimizations of individual molecules with all three density functionals agree that the neutral species are quinoidal as indicated by inversion of short and long bonds compared to aromatic systems. Bond lengths at different levels of theory compared to experimental values are available in SI (Table 1). Frequency analysis confirms that all species are planar. These theoretical predictions are in good agreement with X-ray structures of TDPP-HEX-CN4 and SeDPP-HEX-CN4 with twist angles of less than $10^{\circ}$. Upon reduction, bond length 

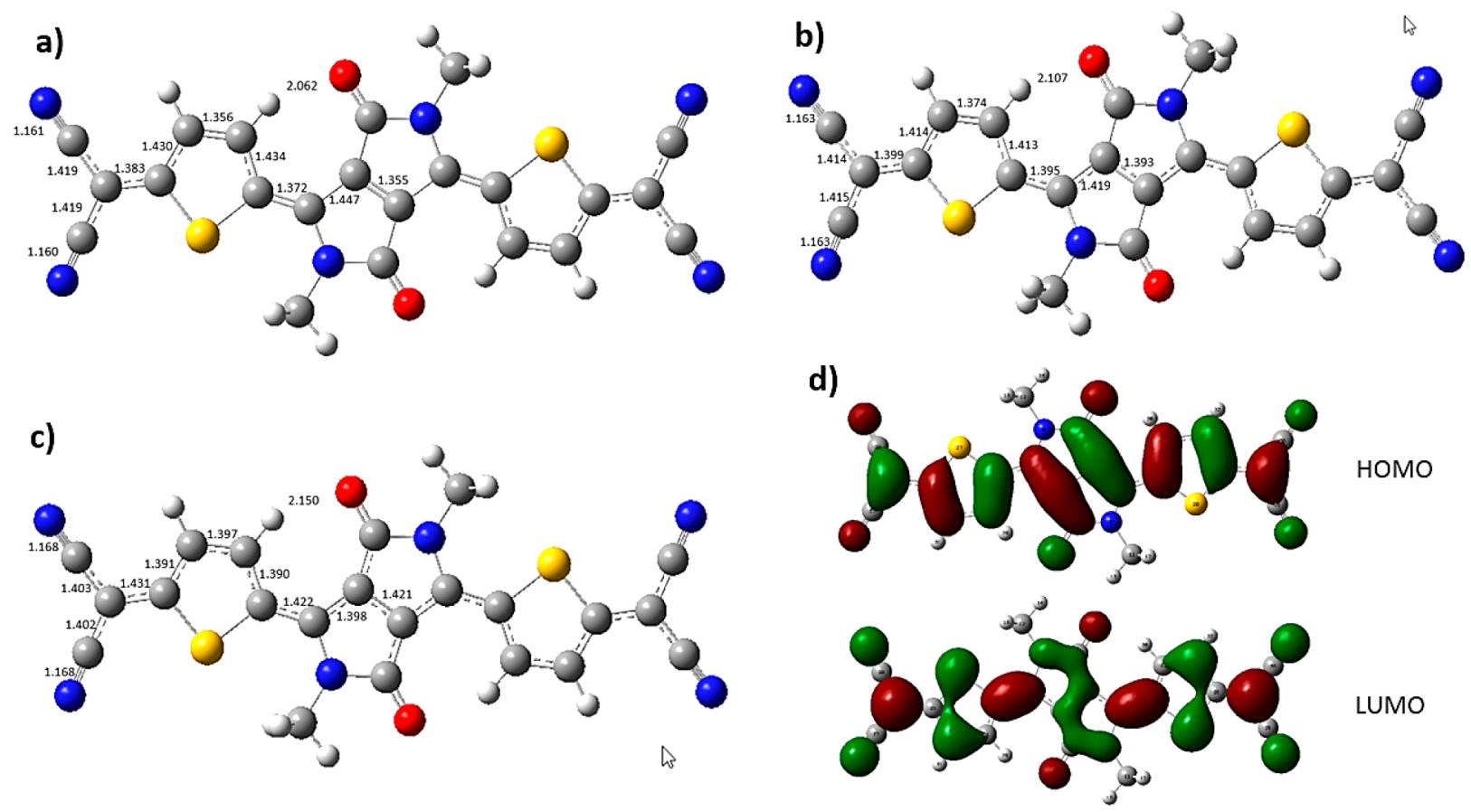

Figure 7. (a) Neutral, (b) anionic, and (c) dianionic forms of TDPP-CN4; (d) calculated frontier molecular orbitals at the B3P86-30\%/6-31+G* level in DCM.

alternation decreases and switches to an aromatic pattern during the second reduction step (Figure 7). In comparison to aromatic thiophene oligomers, the HOMO and LUMO of the neutral form are switched as shown in Figure $7 \mathrm{~d}$ for TDPPCN4. Orbital diagrams are very similar for all systems and are available in theSI (Figure S7-S10).

The structure of the triplet state of TTDPP-CN4 resembles that of the open-shell biradical. Figure 8 depicts the comparison of $\mathrm{C}-\mathrm{C}$ bond lengths optimized for the $\mathrm{T}_{1}$ state with those calculated for the biradical $S_{0}$ state with the $\omega$ B97X-D functional (the only one that produces a biradical). The bond
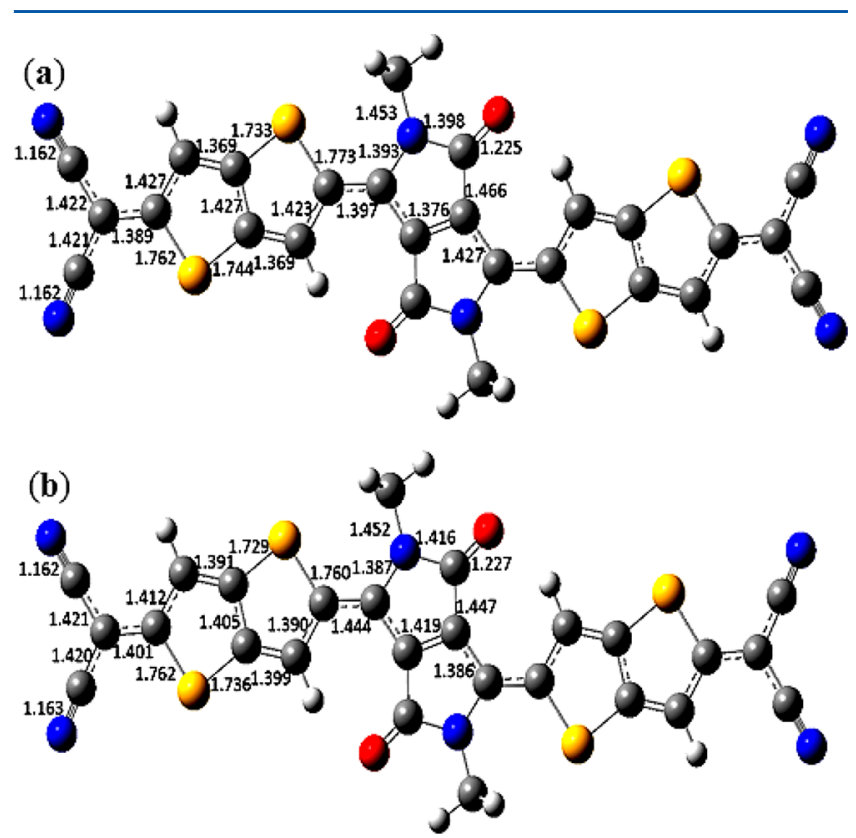

Figure 8. Cyclic open-shell (a) singlet and (b) triplet at $\omega$ B97X-D/6$31+G^{*}$ in DCM. length differences between the open-shell and $\mathrm{T}_{1}$ state are as much as to $0.047 \AA$. In the $T_{1}$ state, the highest Mulliken spin densities (0.44) are located on the methylene carbons of the $=$ $\mathrm{C}(\mathrm{CN})_{2}$ groups and on two $\mathrm{C}$ atoms $(0.33$ and 0.21$)$ of the TT units. In the biradical, the spin densities on neighboring atoms alternate and are distributed over the whole molecule. The reason for these differences is that in the triplet state, one electron occupies the HOMO and the other one occupies the LUMO orbital, which are both distributed over the molecule. In contrast, in the open-shell singlet, the two electrons occupy linear combinations of HOMO and LUMO with maximum electron densities at the ends of the molecule.

3.5. NMR Study. Intrigued by the single-crystal X-ray analysis, the ${ }^{1} \mathrm{H}$ NMR spectra were recorded to confirm the quinoidal structure of DPP derivatives. Since the development of quinoid structure reverses the $\mathrm{C}=\mathrm{C} / \mathrm{C}-\mathrm{C}$ bond length alternating pattern, it enhances or diminishes the double bond character between specific carbon atoms and thereby imposes distinct changes in proton-proton coupling constants. ${ }^{70}$ The coupling constants between thiophene/selenophene $\beta, \beta^{\prime}$ protons $^{67}$ in the aromatic bromides (structures 6,7 in Figure S4) are 4.0 and $4.5 \mathrm{~Hz}$. However, due to double bond character between the $\beta$ and $\beta^{\prime}$ carbons in the quinoid structure, TDPPCN4 and SeDPP-CN4 display enhanced coupling constant values near 5.6 and $6.0 \mathrm{~Hz}$, respectively. The ${ }^{1} \mathrm{H}$ NMR spectra rule out any possible $\mathrm{E} / \mathrm{Z}$ isomerism in these compounds. ${ }^{7}$ This is confirmed by single-crystal X-ray analysis and theory, which show that intramolecular $\mathrm{H}$-bonding between thiophene/ selenophene rings and $\mathrm{C}=\mathrm{O}$ of $\mathrm{DPP}(\mathrm{C}-\mathrm{H} \cdots \mathrm{O}, 2.240 \AA$ for TDPP-Hex-CN4 and $2.229 \AA$ for SeDPP-Hex-CN4) leads to a cis conformation around the double bond between the thiophene/selenophene rings and DPP (Figure S5). ${ }^{1}$ Therefore, NMR spectroscopy in combination with X-ray crystallographic analysis reveals that only $\mathrm{Z}, \mathrm{Z}$-isomers are present.

The variable temperature (VT) ${ }^{1} \mathrm{H}$ NMR studies of TTDPPCN4 (Figure S6), show sharp resonance signals of aromatic 
protons that do not shift throughout the temperature range from 313 to $233 \mathrm{~K}$. Identical NMR spectra in the entire temperature range imply the existence of only one kind of species. The results of the VT ${ }^{1} \mathrm{H}$ NMR experiments and of the theoretical study imply that the ground state of the molecule is closed-shell singlet and triplet state is not thermally accessible.

\section{CONCLUSIONS}

Terminal dicyanomethylene substitution switches the structures of the investigated DPP derivatives from aromatic to quinoid. This induces a tendency to become biradicaloid, which increases with chain length. Theoretical analysis indicates that TTDPP-CN4 species are borderline to the transition from the closed-shell to biradicaloid ground state. The trend toward biradical formation upon chain length increase from TDPPCN4 to TTDPP-CN4 was confirmed theoretically with the bithiophene analog of TDPP-CN4, which is a biradical.

The first and second EA of the three molecules are unusually high for such small molecules. Anions and dianions are shown to be stable under ambient conditions. Together with the strong $\pi-\pi$ stacking in the crystal, this indicates that these molecules have great potential as n-type conductors for organic electronics. Slightly larger species with biradical ground states are candidates for singlet fission. Exploration of cutting edge applications of these systems is currently underway in our laboratory.

\section{ASSOCIATED CONTENT}

\section{S Supporting Information}

The Supporting Information is available free of charge on the ACS Publications website at DOI: 10.1021/acs.jpcc.7b04085.

Experimental procedures, spectral, electrochemical, and photophysical characterizations (PDF)

\section{AUTHOR INFORMATION}

\section{Corresponding Author}

*E-mail: satish@sscu.iisc.ernet.in

ORCID

Satish Patil: 0000-0003-3884-114X

Notes

The authors declare no competing financial interest.

\section{ACKNOWLEDGMENTS}

S.P. acknowledges a research grant from the Ministry of Communication and Information Technology under the Centre of Excellence in Nanoelectronics, Phase II and Department of Science and Technology for Swarnajayanti fellowship. S.R. thanks the University grants commission (UGC), New Delhi for the Dr. D. S. Kothari Postdoctoral fellowship. We sincerely acknowledge the IPC department for NMR and single-crystal X-ray diffractometer facility, and the Proteomics center for ESI. Prodip Howlader and Paramita Das are acknowledged for recording the X-ray and NMR data. S.R. thanks Sushmitha Chandrabhas for her help in completing this work. We acknowledge Dr. Jyotishman Dasgupta and Palas Roy of TIFR, Mumbai for EPR facility.

\section{REFERENCES}

(1) Qiao, Y.; Guo, Y.; Yu, C.; Zhang, F.; Xu, W.; Liu, Y.; Zhu, D. Diketopyrrolopyrrole-Containing Quinoidal Small Molecules for High-Performance, Air-Stable, and Solution-Processable n-Channel
Organic Field-Effect Transistors. J. Am. Chem. Soc. 2012, 134, 40844087.

(2) Wang, C.; Zang, Y.; Qin, Y.; Zhang, Q.; Sun, Y.; Di, C.; Xu, W.; Zhu, D. Thieno[3,2-b]thiophene-Diketopyrrolopyrrole-Based Quinoidal Small Molecules: Synthesis, Characterization, Redox Behavior, and n-Channel Organic Field-Effect Transistors. Chem. - Eur. J. 2014, 20, 13755-13761.

(3) Zhong, H.; Smith, J.; Rossbauer, S.; White, A. J. P.; Anthopoulos, T. D.; Heeney, M. Air-Stable and High-Mobility n-Channel Organic Transistors Based on Small-Molecule/Polymer Semiconducting Blends. Adv. Mater. 2012, 24, 3205-3211.

(4) Casado, J.; Miller, L. L.; Mann, K. R.; Pappenfus, T. M.; Higuchi, H.; Ortí, E.; Milián, B.; Pou-Amerígo, R.; Hernández, V.; López Navarrete, J. T. Quinonoid Oligothiophenes as Electron-Donor and Electron-Acceptor Materials. A Spectroelectrochemical and Theoretical Study. J. Am. Chem. Soc. 2002, 124, 12380-12388.

(5) Pappenfus, T. M.; Chesterfield, R. J.; Frisbie, C. D.; Mann, K. R.; Casado, J.; Raff, J. D.; Miller, L. L. A $\pi$-Stacking Terthiophene-Based Quinodimethane is an n-Channel Conductor in a Thin Film Transistor. J. Am. Chem. Soc. 2002, 124, 4184-4185.

(6) Janzen, D. E.; Burand, M. W.; Ewbank, P. C.; Pappenfus, T. M.; Higuchi, H.; da Silva Filho, D. A.; Young, V. G.; Bredas, J. L.; Mann, K. R. Preparation and Characterization of $\pi$-Stacking Quinodimethane Oligothiophenes. Predicting Semiconductor Behavior and Bandwidths from Crystal Structures and Molecular Orbital Calculations. J. Am. Chem. Soc. 2004, 126, 15295-15308.

(7) Nakano, M.; Osaka, I.; Takimiya, K. Dibenzo[a,e]pentaleneEmbedded Dicyanomethylene-Substituted Thienoquinoidals for $\mathrm{n}$ Channel Organic Semiconductors: Synthesis, Properties, and Device Characteristics. J. Mater. Chem. C 2015, 3, 283-290.

(8) Li, J.; Qiao, X.; Xiong, Y.; Li, H.; Zhu, D. Five-Ring Fused Tetracyanothienoquinoids as High-Performance and Solution-Processable n-Channel Organic Semiconductors: Effect of the Branching Position of Alkyl Chains. Chem. Mater. 2014, 26, 5782-5788.

(9) Di Motta, S.; Negri, F.; Fazzi, D.; Castiglioni, C.; Canesi, E. V. Biradicaloid and Polyenic Character of Quinoidal Oligothiophenes Revealed by the Presence of a Low-Lying Double-Exciton State. J. Phys. Chem. Lett. 2010, 1, 3334-3339.

(10) Fabian, J.; Nakazumi, H.; Matsuoka, M. Near-Infrared Absorbing Dyes. Chem. Rev. 1992, 92, 1197-1226.

(11) Ren, L.; Liu, F.; Shen, X.; Zhang, C.; Yi, Y.; Zhu, X. Z. Developing Quinoidal Fluorophores with Unusually Strong Red/ Near-Infrared Emission. J. Am. Chem. Soc. 2015, 137, 11294-11302.

(12) Shi, X.; Quintero, E.; Lee, S.; Jing, L.; Herng, T. S.; Zheng, B.; Huang, K. W.; López Navarrete, J. T.; Ding, J.; Kim, D.; et al. BenzoThia-Fused $[n]$ Thienoacenequinodimethanes With Small to Moderate Diradical Characters: the Role of Pro-Aromaticity Versus AntiAromaticity. Chem. Sci. 2016, 7, 3036-3046.

(13) Kishi, R.; Dennis, M.; Fukuda, K.; Murata, Y.; Morita, K.; Uenaka, H.; Nakano, M. Theoretical Study on the Electronic Structure and Third-Order Nonlinear Optical Properties of Open-Shell Quinoidal Oligothiophenes. J. Phys. Chem. C 2013, 117, 2149821508.

(14) Kishi, R.; Murata, Y.; Saito, M.; Morita, K.; Abe, M.; Nakano, M. Theoretical Study on the Electronic Structure and Third-Order Nonlinear Optical Properties of Open-Shell Quinoidal Oligothiophenes. J. Phys. Chem. A 2014, 118, 10837-10848.

(15) Ponce Ortiz, R.; Casado, J.; Hernández, V.; López Navarrete, J. T.; Viruela, P. M.; Ortí, E.; Takimiya, K.; Otsubo, T. On the Biradicaloid Nature of Long Quinoidal Oligothiophenes: Experimental Evidence Guided by Theoretical Studies. Angew. Chem. 2007, 119, 9215-9219.

(16) Lim, Z.; Zheng, B.; Huang, K. W.; Liu, Y.; Wu, J. Quinoidal Oligo(9,10-anthryl)s with Chain-Length-Dependent Ground States: A Balance between Aromatic Stabilization and Steric Strain Release. Chem. - Eur. J. 2015, 21, 18724-18729.

(17) Zeng, Z.; Lee, S.; Zafra, J. L.; Ishida, M.; Bao, N.; Webster, R. D.; López Navarrete, J. T.; Ding, J.; Casado, J.; Kim, D.; et al. Turning on the Biradical State of Tetracyano-Perylene and Quaterrylenequi- 
nodimethanes by Incorporation of Additional Thiophene Rings. Chem. Sci. 2014, 5, 3072-3080.

(18) Canesi, E. V.; Fazzi, D.; Colella, L.; Bertarelli, C.; Castiglioni, C. Tuning the Quinoid versus Biradicaloid Character of Thiophene-Based Heteroquaterphenoquinones by Means of Functional Groups. J. Am. Chem. Soc. 2012, 134, 19070-19083.

(19) Zeng, Z.; Shi, X.; Chi, C.; López Navarrete, J. T.; Casado, J.; Wu, J. Pro-Aromatic and Anti-Aromatic $\pi$-Conjugated Molecules: an Irresistible Wish to be Diradicals. Chem. Soc. Rev. 2015, 44, 65786596.

(20) Shi, X.; Burrezo, P. M.; Lee, S.; Zhang, W.; Zheng, B.; Dai, G.; Chang, J.; López Navarrete, J. T.; Huang, K. W.; Kim, D.; et al. Antiaromatic Bisindeno- $[n]$ thienoacenes With Small Singlet Biradical Characters: Syntheses, Structures and Chain Length Dependent Physical Properties. Chem. Sci. 2014, 5, 4490-4503.

(21) Konishi, A.; Hirao, Y.; Nakano, M.; Shimizu, A.; Botek, E.; Champagne, B.; Shiomi, D.; Sato, K.; Takui, T.; Matsumoto, K.; et al. Synthesis and Characterization of Teranthene: A Singlet Biradical Polycyclic Aromatic Hydrocarbon Having Kekulé Structures. J. Am. Chem. Soc. 2010, 132, 11021-11023.

(22) Hernandez, V.; Losada, S. C.; Casado, J.; Higuchi, H.; López Navarrete, J. T. Combined Theoretical and Vibrational Study of Dihexylbithienoquinonoid Derivatives with Regioregular Head-toHead, Head-to-Tail, and Tail-to-Tail Orientations. J. Phys. Chem. A 2000, 104, 661-672.

(23) Takahashi, T.; Matsuoka, K. I.; Takimiya, K.; Otsubo, T.; Aso, Y. Extensive Quinoidal Oligothiophenes with Dicyanomethylene Groups at Terminal Positions as Highly Amphoteric Redox Molecules. J. Am. Chem. Soc. 2005, 127, 8928-8929.

(24) Das, S.; Herng, T. S.; Zafra, J. L.; Burrezo, P. M.; Kitano, M.; Ishida, M.; Gopalakrishna, T. Y.; Hu, P.; Osuka, A.; Casado, J.; et al. Fully Fused Quinoidal/Aromatic Carbazole Macrocycles with Polyradical Characters. J. Am. Chem. Soc. 2016, 138, 7782-7790.

(25) Takimiya, K.; Shinamura, S.; Osaka, I.; Miyazaki, E. Thienoacene-Based Organic Semiconductors. Adv. Mater. 2011, 23, $4347-4370$.

(26) Takeda, T.; Akutagawa, T. Preparation, Structure, and Redox Behavior of Bis(diarylmethylene)dihydrothiophene and Its $\pi$-Extended Analogues. J. Org. Chem. 2015, 80, 2455-2461.

(27) Hibi, D.; Kitabayashi, K.; Fujita, K.; Takeda, T.; Tobe, Y. Diindenopyrenes: Extended 1,6- and 1,8-Pyrenoquinodimethanes with Singlet Diradical Characters. J. Org. Chem. 2016, 81, 3735-3743.

(28) Hu, P.; Lee, S.; Herng, T. S.; Aratani, N.; Goncalves, T. P.; Qi, Q.; Shi, X.; Yamada, H.; Huang, K. W.; Ding, J.; et al. Toward Tetraradicaloid: The Effect of Fusion Mode on Radical Character and Chemical Reactivity. J. Am. Chem. Soc. 2016, 138, 1065-1077.

(29) Ohashi, K.; Kubo, T.; Masui, T.; Yamamoto, K.; Nakasuji, K.; Takui, T.; Kai, Y.; Murata, I. 4,8,12,16-Tetra-tert-butyl-s-indaceno$\left[1,2,3-c d: 5,6,7-c^{c} d^{c}\right]$ diphenalene: A Four-Stage Amphoteric Redox System. J. Am. Chem. Soc. 1998, 120, 2018-2027.

(30) Shimizu, A.; Uruichi, M.; Yakushi, K.; Matsuzaki, H.; Okamoto, H.; Nakano, M.; Hirao, Y.; Matsumoto, K.; Kurata, H.; Kubo, T. Resonance Balance Shift in Stacks of Delocalized Singlet Biradicals. Angew. Chem., Int. Ed. 2009, 48, 5482-5486.

(31) Shimizu, A.; Hirao, Y.; Matsumoto, K.; Kurata, H.; Kubo, T.; Uruichi, M.; Yakushi, K. Aromaticity and $\pi$-Bond Covalency: Prominent Intermolecular Covalent Bonding Interaction of a Kekulé Hydrocarbon With Very Significant Singlet Biradical Character. Chem. Commun. 2012, 48, 5629-5631.

(32) Wu, T. C.; Chen, C. H.; Hibi, D.; Shimizu, A.; Tobe, Y.; Wu, Y. T. Synthesis, Structure, and Photophysical Properties of Dibenzo[de,mn]naphthacenes. Angew. Chem., Int. Ed. 2010, 49, 7059-7062.

(33) Shan, L.; Liang, Z. X.; Xu, X. M.; Tang, Q.; Miao, Q. Revisiting Zethrene: Synthesis, Reactivity and Semiconductor Properties. Chem. Sci. 2013, 4, 3294-3297.

(34) Shi, X.; Lee, S.; Son, M.; Zheng, B.; Chang, J.; Jing, L.; Huang, K. W.; Kim, D.; Chi, C. Pro-Aromatic Bisphenaleno-thieno[3,2$b]$ thiophene Versus Anti-aromatic Bisindeno-thieno[3,2-b]thiophene:
Different Ground-state Properties and Applications in Field-Effect Transistors. Chem. Commun. 2015, 51, 13178-13180.

(35) Chase, D. T.; Rose, B. D.; McClintock, S. P.; Zakharov, L. N.; Haley, M. M. Indeno[1,2-b]fluorenes: Fully Conjugated Antiaromatic Analogues of Acenes. Angew. Chem., Int. Ed. 2011, 50, 1127-1130.

(36) Shimizu, A.; Kishi, R.; Nakano, M.; Shiomi, D.; Sato, K.; Takui, T.; Hisaki, I.; Miyata, M.; Tobe, Y. Indeno[2,1-b]fluorene: A 20- $\pi$ Electron Hydrocarbon with Very Low-Energy Light Absorption. Angew. Chem., Int. Ed. 2013, 52, 6076-6079.

(37) Young, B. S.; Chase, D. T.; Marshall, J. L.; Vonnegut, C. L.; Zakharov, L. N.; Haley, M. M. Synthesis and Properties of FullyConjugated Indacenedithiophenes. Chem. Sci. 2014, 5, 1008-1014.

(38) Zhu, X.; Tsuji, H.; Nakabayashi, H.; Ohkoshi, S.; Nakamura, E. Air- and Heat-Stable Planar Tri-p-Quinodimethane with Distinct Biradical Characteristics. J. Am. Chem. Soc. 2011, 133, 16342-16345.

(39) Smith, M. B.; Michl, J. Singlet Fission. Chem. Rev. 2010, 110, 6891-6936.

(40) Lee, J.; Jadhav, P.; Reusswig, P. D.; Yost, S. R.; Thompson, N. J.; Congreve, D. N.; Hontz, E.; Van Voorhis, T.; Baldo, M. A. Singlet Exciton Fission Photovoltaics. Acc. Chem. Res. 2013, 46, 1300-1311.

(41) Chikamatsu, M.; Mikami, T.; Chisaka, J.; Yoshida, Y.; Azumi, R.; Yase, K. Ambipolar Organic Field-Effect Transistors Based on a Low Band Gap Semiconductor with Balanced Hole and Electron Mobilities. Appl. Phys. Lett. 2007, 91, 043506.

(42) Chase, D. T.; Fix, A. G.; Kang, S. J.; Rose, B. D.; Weber, C. D.; Zhong, Y.; Zakharov, L. N.; Lonergan, M. C.; Nuckolls, C.; Haley, M. M. 6,12-Diarylindeno[1,2-b]fluorenes: Syntheses, Photophysics, and Ambipolar OFETs. J. Am. Chem. Soc. 2012, 134, 10349-10352.

(43) Kamada, K.; Ohta, K.; Kubo, T.; Shimizu, A.; Morita, Y.; Nakasuji, K.; Kishi, R; Ohta, S.; Furukawa, S. I.; Takahashi, H.; et al. Strong Two-Photon Absorption of Singlet Diradical Hydrocarbons. Angew. Chem., Int. Ed. 2007, 46, 3544-3546.

(44) Son, Y. W.; Cohen, M. L.; Louie, S. G. Energy Gaps in Graphene Nanoribbons. Phys. Rev. Lett. 2006, 97, 216803.

(45) Dediu, V.; Hueso, L. E.; Bergenti, I.; Taliani, C. Spin Routes in Organic Semiconductors. Nat. Mater. 2009, 8, 707-716.

(46) Morita, Y.; Nishida, S.; Murata, T.; Moriguchi, M.; Ueda, A.; Satoh, M.; Arifuku, K.; Sato, K.; Takui, T. Organic Tailored Batteries Materials Using Stable Open-Shell Molecules with Degenerate Frontier Orbitals. Nat. Mater. 2011, 10, 947-951.

(47) Shin, J. Y.; Yamada, T.; Yoshikawa, H.; Awaga, K.; Shinokubo, H. An Antiaromatic Electrode-Active Material Enabling High Capacity and Stable Performance of Rechargeable Batteries. Angew. Chem., Int. Ed. 2014, 53, 3096-3101.

(48) Nakano, M.; Kishi, R.; Nitta, T.; Kubo, T.; Nakasuji, K.; Kamada, K.; Ohta, K.; Champagne, B.; Botek, E.; Yamaguchi, K. Second Hyperpolarizability $(\gamma)$ of Singlet Diradical System: Dependence of $\gamma$ on the Diradical Character. J. Phys. Chem. A 2005, 109, 885891.

(49) Nakano, M.; Kishi, R.; Ohta, S.; Takahashi, H.; Kubo, T.; Kamada, K.; Ohta, K.; Botek, E.; Champagne, B. Relationship between Third-Order Nonlinear Optical Properties and Magnetic Interactions in Open-Shell Systems: A New Paradigm for Nonlinear Optics. Phys. Rev. Lett. 2007, 99, 033001-033004.

(50) Tschitschibabin, A. E. Über Einige Phenylierte Derivate Des $p$, p-Ditolyls. Ber. Dtsch. Chem. Ges. 1907, 40, 1810-1819.

(51) Porter, W. W., III; Vaid, T. P.; Rheingold, A. L. Synthesis and Characterization of a Highly Reducing Neutral "Extended Viologen" and the Isostructural Hydrocarbon 4,4“"'-Di- $n$-octyl-p-quaterphenyl. J. Am. Chem. Soc. 2005, 127, 16559-16566.

(52) Thiele, J.; Balhorn, H. Ueber Einen Chinoïden Kohlenwasserstoff. Ber. Dtsch. Chem. Ges. 1904, 37, 1463-1470.

(53) Flynn, C. R.; Michl, J. $\pi, \pi$-Biradicaloid Hydrocarbons: oXylylene. Photochemical Preparation from 1,4-Dihydrophthalazine in Rigid Glass, Electronic Spectroscopy, and Calculations. J. Am. Chem. Soc. 1974, 96, 3280-3288.

(54) Acker, D. S.; Hertler, W. R. Substituted Quinodimethans. I. Preparation and Chemistry of 7,7,8,8-Tetracyanoquinodimethan. J. Am. Chem. Soc. 1962, 84, 3370-3374. 
(55) Zeng, Z.; Lee, S.; Son, M.; Fukuda, K.; Burrezo, P. M.; Zhu, X.; Qi, Q.; Li, R. W.; Navarrete, J. T. L.; Ding, J.; et al. Push-Pull Type Oligo( $N$-annulated perylene)quinodimethanes: Chain Length and Solvent-Dependent Ground States and Physical Properties. J. Am. Chem. Soc. 2015, 137, 8572-8583.

(56) Brown, A. R.; de Leeuw, D. M.; Lous, E. J.; Havinga, E. E. Organic n-Type Field-Effect Transistor. Synth. Met. 1994, 66, 257261.

(57) Laquindanum, J. G.; Katz, H. E.; Dodabalapur, A.; Lovinger, A. J. n-Channel Organic Transistor Materials Based on Naphthalene Frameworks. J. Am. Chem. Soc. 1996, 118, 11331-11332.

(58) Wang, C.; Qin, Y.; Sun, Y.; Guan, Y. S.; Xu, W.; Zhu, D. Thiophene-Diketopyrrolopyrrole-Based Quinoidal Small Molecules as Solution-Processable and Air-Stable Organic Semiconductors: Tuning of the Length and Branching Position of the Alkyl Side Chain toward a High-Performance $\mathrm{n}$-Channel Organic Field-Effect Transistor. ACS Appl. Mater. Interfaces 2015, 7, 15978-15987.

(59) Chesterfield, R. J.; Newman, C. R.; Pappenfus, T. M.; Ewbank, P. C.; Haukaas, M. H.; Mann, K. R.; Miller, L. L.; Frisbie, C. D. High Electron Mobility and Ambipolar Transport in Organic Thin-Film Transistors Based on a $\pi$-Stacking Quinoidal Terthiophene. Adv. Mater. 2003, 15, 1278-1282.

(60) Berlin, A.; Grimoldi, S.; Zotti, G.; Osuna, R. M.; Ruiz Delgado, M. C.; Ortiz, R. P.; Casado, J.; Hernandez, V.; López Navarrete, J. T. Synthesis and Characterization of a Novel Terthiophene-Based Quinodimethane Bearing a 3,4-Ethylenedioxythiophene Central Unit. J. Phys. Chem. B 2005, 109, 22308-22318.

(61) Handa, S.; Miyazaki, E.; Takimiya, K.; Kunugi, Y. SolutionProcessible n-Channel Organic Field-Effect Transistors Based on Dicyanomethylene-Substituted Terthienoquinoid Derivative. J. Am. Chem. Soc. 2007, 129, 11684-11685.

(62) Frisch, M. J.; Trucks, G. W.; Schlegel, H. B.; Scuseria, G. E.; Robb, M. A.; Cheeseman, J. R.; Scalmani, G.; Barone, V.; Mennucci, B.; Petersson, G. A.; Nakatsuji, H.; Caricato, M.; Li, X.; Hratchian, H. P.; Izmaylov, A. F.; Bloino, J.; Zheng, G.; Sonnenberg, J. L.; Hada, M.; Ehara, M.; Toyota, K.; Fukuda, R.; Hasegawa, J.; Ishida, M.; Nakajima, T.; Honda, Y.; Kitao, O.; Nakai, H.; Vreven, T.; Montgomery, J. A., Jr.; Peralta, J. E.; Ogliaro, F.; Bearpark, M.; Heyd, J. J.; Brothers, E.; Kudin, K. N.; Staroverov, V. N.; Kobayashi, R.; Normand, J.; Raghavachari, K.; Rendell, A.; Burant, J. C.; Iyengar, S. S.; Tomasi, J.; Cossi, M.; Rega, N.; Millam, J. M.; Klene, M.; Knox, J. E.; Cross, J. B.; Bakken, V.; Adamo, C.; Jaramillo, J.; Gomperts, R.; Stratmann, R. E.; Yazyev, O.; Austin, A. J.; Cammi, R.; Pomelli, C.; Ochterski, J. W.; Martin, R. L.; Morokuma, K.; Zakrzewski, V. G.; Voth, G. A.; Salvador, P.; Dannenberg, J. J.; Dapprich, S.; Daniels, A. D.; Farkas, O.; Foresman, J. B.; Ortiz, J. V.; Cioslowski, J.; Fox, D. J. Gaussian 09, revision D.01; Gaussian, Inc.: Wallingford, CT, 2009.

(63) Yamaguchi, K. The Electronic Structures of Biradicals in the Unrestricted Hartree-Fock Approximation. Chem. Phys. Lett. 1975, 33, 330-335.

(64) Davidson, E. R; Clark, A. E. Spin Polarization and Anihilation for Radicals and Diradicals. Int. J. Quantum Chem. 2005, 103, 1-9.

(65) Salzner, U.; Aydin, A. Improved Prediction of Properties of $\pi$ Conjugated Oligomers with Range-Separated Hybrid Density Functionals. J. Chem. Theory Comput. 2011, 7, 2568-2583.

(66) Uno, M.; Seto, K.; Takahashi, S. A New Method of Synthesis of Arylmalononitriles Catalysed by a Palladium Complex. J. Chem. Soc., Chem. Commun. 1984, 932-933.

(67) Dhar, J.; Venkatramaiah, N.; Anitha, A.; Patil, S. Photophysical, Electrochemical and Solid State Properties of Diketopyrrolopyrrole Based Molecular Materials: Importance of the Donor Group. J. Mater. Chem. C 2014, 2, 3457-3466.

(68) Zhang, L.; Fakhouri, S. M.; Liu, F.; Timmons, J. C.; Ran, N. A.; Briseno, A. L. Chalcogenoarene Semiconductors: New Ideas from Old Materials. J. Mater. Chem. 2011, 21, 1329-1337.

(69) Murphy, A. R.; Frechet, J. M. J. Organic Semiconducting Oligomers for Use in Thin Film Transistors. Chem. Rev. 2007, 107, 1066-1096.
(70) Pappenfus, T. M.; Raff, J. D.; Hukkanen, E. J.; Burney, J. R.; Casado, J.; Drew, S. M.; Miller, L. L.; Mann, K. R. Dinitro and Quinodimethane Derivatives of Terthiophene That Can Be Both Oxidized and Reduced. Crystal Structures, Spectra, and a Method for Analyzing Quinoid Contributions to Structure. J. Org. Chem. 2002, 67, 6015-6024.

(71) Ponce Ortiz, R.; Casado, J.; Hernández, V.; López Navarrete, J. T.; Orti, E.; Viruela, P. M.; Milian, B.; Hotta, S.; Zotti, G.; Zecchin, S.; et al. Magnetic Properties of Quinoidal Oligothiophenes: More Than Good Candidates for Ambipolar Organic Semiconductors. Adv. Funct. Mater. 2006, 16, 531-536.

(72) Anthony, J. E.; Eaton, D. L.; Parkin, S. R. A Road Map to Stable, Soluble, Easily Crystallized Pentacene Derivatives. Org. Lett. 2002, 4, $15-18$.

(73) Lim, Y. F.; Shu, Y.; Parkin, S. R.; Anthony, J. E.; Malliaras, G. G. Soluble n-Type Pentacene Derivatives as Novel Acceptors for Organic Solar Cells. J. Mater. Chem. 2009, 19, 3049-3056. 